\title{
Effect of fat content on the physical properties and consumer acceptability of vanilla ice cream
}

\author{
M. Laura Rolon, ${ }^{*}$ Alyssa J. Bakke, ${ }^{*} \dagger$ John N. Coupland, ${ }^{*}$ John E. Hayes, ${ }^{*} \dagger$ and Robert F. Roberts ${ }^{* 1}$ \\ *Department of Food Science, and \\ †Sensory Evaluation Center, The Pennsylvania State University, University Park 16802
}

\begin{abstract}
Ice cream is a complex food matrix that contains multiple physical phases. Removal of 1 ingredient may affect not only its physical properties but also multiple sensory characteristics that may or may not be important to consumers. Fat not only contributes to texture, mouth feel, and flavor, but also serves as a structural element. We evaluated the effect of replacing fat with maltodextrin (MD) on select physical properties of ice cream and on consumer acceptability. Vanilla ice creams were formulated to contain $6,8,10,12$, and $14 \%$ fat, and the difference was made up with $8,6,4,2$, and $0 \%$ maltodextrin, respectively, to balance the mix. Physical characterization included measurements of overrun, apparent viscosity, fat particle size, fat destabilization, hardness, and melting rate. A series of sensory tests were conducted to measure liking and the intensity of various attributes. Tests were also conducted after 19 weeks of storage at $-18^{\circ} \mathrm{C}$ to assess changes in acceptance due to prolonged storage at unfavorable temperatures. Then, discrimination tests were performed to determine which differences in fat content were detectable by consumers. Mix viscosity decreased with increasing fat content and decreasing maltodextrin content. Fat particle size and fat destabilization significantly increased with increasing fat content. However, acceptability did not differ significantly across the samples for fresh or stored ice cream. Following storage, ice creams with 6,12 , and $14 \%$ fat did not differ in acceptability compared with fresh ice cream. However, the $8 \%$ fat, $6 \% \mathrm{MD}$ and $10 \%$ fat, $4 \% \mathrm{MD}$ ice creams showed a significant drop in acceptance after storage relative to fresh ice cream at the same fat content. Consumers were unable to detect a difference of 2 percentage points in fat level between 6 and $12 \%$ fat. They were able to detect a difference of 4 percentage points for ice creams with $6 \%$ versus $10 \%$, but not for those with $8 \%$ versus $12 \%$ fat. Removing
\end{abstract}

Received November 30, 2016.

Accepted March 9, 2017.

${ }^{1}$ Corresponding author: Bob.Roberts@psu.edu fat and replacing it with maltodextrin caused minimal changes in physical properties in ice cream and mix and did not change consumer acceptability for either fresh or stored ice cream.

Key words: ice cream, fat reduction, maltodextrin, consumer acceptability

\section{INTRODUCTION}

Ice cream consists of fat as partially destabilized droplets, air in small bubbles, casein micelles in colloidal suspension, water in the form of ice crystals, and a concentrated unfrozen aqueous solution (Goff and Hartel, 2013). Fat plays a key role as a structural agent, aids in the stabilization of the air phase (Goff et al., 1999), and creates the characteristic sensory qualities that are expected of ice cream (Méndez-Velasco and Goff, 2012). Fat also affects the release of hydrophobic flavor molecules (McClements, 2015). In the United States, the standard of identity of ice cream requires a minimum milk fat content of $10 \%$ (21CFR $\$ 135.110$; FDA, 2016).

Fat reduction is a means of eliminating calories from food, because fat provides more energy per gram than other macronutrients. Further, given the high cost of milk fat, manufacturers may be motivated to cut costs by reducing fat. However, it is widely believed that consumers tend to consider reduced-fat products to be lower in quality (Da Silva et al., 2014).

One way to reduce fat in ice cream involves simply replacing it with water (Roland et al., 1999a). This strategy results in a lower solids mix and lower viscosity (Specter and Setser, 1994; Li et al., 1997), an increase in hardness, and a faster melting rate (Guinard et al., 1997; Prindiville et al., 1999; Roland et al., 1999a). More commonly, fat is replaced with a bulking agent (McClements, 2015) to provide structural support (Roland et al., 1999a) and improve sensory properties (Conforti, 1994; Stampanoni Koeferli et al., 1996; Guinard et al., 1997). Bulking agents are usually carbohydrate or protein ingredients, used because of their lower energy content relative to fat and their water adsorption prop- 
erties (Akoh, 1998). Maltodextrins, polysaccharides produced by partial hydrolysis of starch (Sonwane and Hembade, 2014), are a common bulking ingredient in frozen desserts. The use of maltodextrin, polydextrose, and inulin in reduced-fat ice cream mix has been shown to increase viscosity (Schmidt et al., 1993; Aykan et al., 2008) and produce fast-melting frozen desserts (Ohmes et al., 1998; Roland et al., 1999b; Tiwari et al., 2015). The use of maltodextrin in $2 \%$ fat ice milk yielded a product with higher viscosity and lower whipping ability than ice creams that contained protein ingredients as bulking agents (Schmidt et al., 1993). Importantly, the use of maltodextrin in nonfat ice creams resulted in sensory ratings closer to those of a control ice cream with $10 \%$ fat (Roland et al., 1999b).

Few studies have focused on the effect of fat removal on consumer acceptability. Guinard et al. (1996) observed a small increase due to changes in fat content when no replacement strategy was involved. However, consumer acceptability of chocolate ice creams did not vary when fat content ranged from 0.5 to $10 \%$ fat and when polydextrose or whey protein were used as bulking agents (Prindiville et al., 1999). On the other hand, $\mathrm{Li}$ et al. (1997) reported a decrease in liking when fat was reduced and replaced with polydextrose.

Many previous studies have used descriptive analyses to quantify the sensory attributes thought to be critical to ice cream liking in the context of fat reduction, but very few have compared the acceptability of reduced-fat frozen desserts to consumers. Thus, it remains unknown whether sensory changes detected by trained panelists correspond to meaningful differences in acceptability by naïve consumers. Specifically, the extent to which fat can be replaced without affecting liking has not been adequately explored. The objectives of this study were to (1) investigate the effect of fat reduction using maltodextrin as a bulking agent on select physical properties of ice cream mix and finished ice cream; (2) assess the consumer acceptability of fresh and stored ice creams; and (3) determine whether consumers could discriminate between vanilla ice creams based on their fat content.

\section{MATERIALS AND METHODS}

\section{Formulation and Manufacture of Ice Cream}

Pasteurized whole milk, pasteurized cream, sucrose, 36 DE (dextrose equivalent) corn syrup solids, and nonfat dried milk were provided by the Berkey Creamery (University Park, PA). Maltodextrin (10 DE) was kindly provided by Tate \& Lyle (Star-dri 100; London, UK). A commercially available stabilizer-emulsifier blend (Grindsted IcePro 2005 SH; DuPont, Wilmington, DE) was used; this blend is composed of propylene glycol mono-esters, mono- and diglycerides, cellulose gum, guar gum, and carrageenan with silicon dioxide added as an anticaking agent.

Vanilla ice creams were formulated with milk fat content ranging from 6 to $14 \%$ in increments of 2 percentage points, and maltodextrin was added to compensate for the loss of fat. The level of milk solids nonfat, sugar, corn syrup solids, and stabilizer-emulsifier blend was kept constant throughout the treatments (Table 1). All mixes were formulated using TechWizard version 4 (Owl Software, Columbia, MO) for a $35-\mathrm{kg}$ batch per treatment.

Wet (milk and cream) and dry (sucrose, nonfat dried milk, corn syrup solids, maltodextrin, and the stabilizeremulsifier blend) ingredients were weighed separately and blended under low-speed agitation for $20 \mathrm{~min}$ at room temperature to allow for complete dispersion of the solids. The mixes were pasteurized (HTST) in an APV Junior Pasteurizer (APV Invensys, Woodstock, GA) at $80^{\circ} \mathrm{C}$ for $25 \mathrm{~s}$ and homogenized (Gaulin, Lake Mills, WI) in a 2-stage process applying pressure of 10.3 and $3.5 \mathrm{MPa}$. Following pasteurization, the cooled mix $\left(7^{\circ} \mathrm{C}\right)$ was collected into milk cans and stored at refrigeration temperature $\left(<7^{\circ} \mathrm{C}\right)$ for $48 \mathrm{~h}$. After aging, samples were collected for physical and microbiological analysis. Before freezing, all mixes were flavored (4.45 $\mathrm{mL} / \mathrm{kg}$ mix) with 2-fold vanilla extract (David Michael \& Co., Philadelphia, PA). A continuous freezer (Gram IF 600; Gram Equipment Inc., Northvale, NJ) was used to freeze the mixes into ice cream, with overrun set at

Table 1. Vanilla ice cream formulations with decreasing fat content and replacement with maltodextrin (MD)

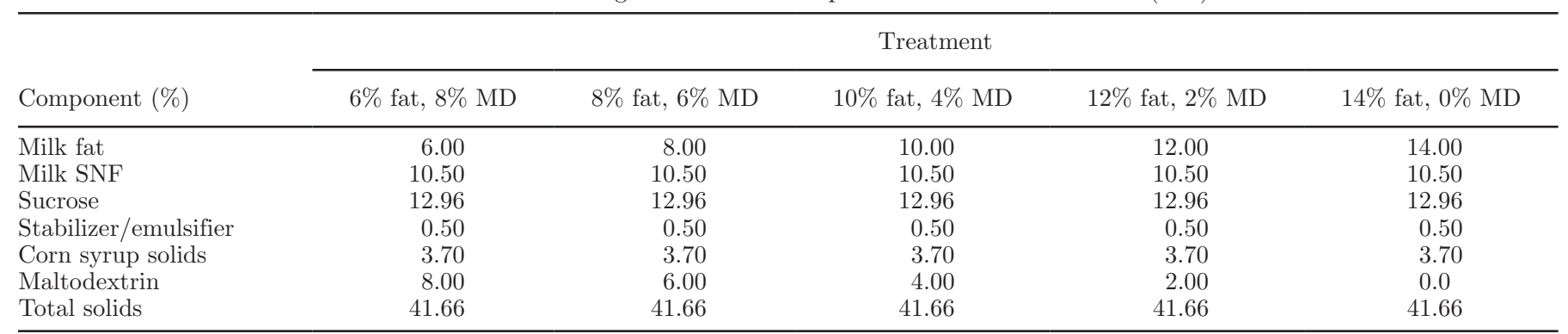


$65 \%$. The resulting product was packaged (Compact Single Line Rotary Filler; T. D. Sawvel Co. Inc., Maple Plain, MN) into 118-mL (4-ounce) cups, coded with a 3 -digit blinding code, and kept in a $-35^{\circ} \mathrm{C}$ hardening room. Three days before sensory testing, the ice creams were allowed to temper in a $-18^{\circ} \mathrm{C}$ freezer. All ice creams were tested for total aerobic bacteria and highsensitivity coliform counts (Petrifilm; 3M, Maplewood, $\mathrm{MN}$ ) to ensure suitability for human consumption.

\section{Physical Analysis}

Compositional and Manufacturing Attributes. Fat and total solids contents were measured using Smart Track (CEM Corporation, Matthews, NC). The density of each mix was measured by weighing a fixed volume (Goff and Hartel, 2013). Draw temperature was measured during ice cream production using a calibrated thermocouple. Overrun was measured by comparing the weight of a full pint $(473 \mathrm{~mL})$ of ice cream to the weight of a full pint of mix (Adapa et al., 2000).

Physical Characterization. An orifice type viscometer (Zahn cup \#2; Boekel Scientific, Feasterville, PA) was used to quantify the kinematic viscosity of the mixes after aging (ASTM International, 2005). Aged mixes were also analyzed with a rheometer (Discovery HR-3; TA Instruments, New Castle, DE) using a 25 $\mathrm{mm}$ parallel plate geometry with shear rates ranging from 0 to $80 \mathrm{~s}^{-1}$ at a constant temperature of $25^{\circ} \mathrm{C}$. Flow curves were plotted with Trios Software (TA Instruments, New Castle, DE) and modeled using the Herschel-Bulkley equation. Apparent viscosity was calculated as the ratio of stress to rate of strain at $30 \mathrm{~s}^{-1}$. The particle size of the milk fat globules was assessed in the mix after aging and in the ice cream using static light scattering (Horiba LA-920; Horiba Scientific, Kyoto, Japan). Deionized water was used as the diluent, and the relative refractive index was set at 1.14 , calculated as the refractive index of the particle (1.52 for milk fat) divided by the refractive index of the diluent (1.33 for water). Drops of aged mix or a portion of frozen ice cream were added into the chamber until transmittance equilibrated between 70 and $95 \%$. The temperature was maintained between 40 and $45^{\circ} \mathrm{C}$ to ensure the milk fat was in a liquid state. From the particle-size distributions obtained, the volume-weighted mean $\left(\mathbf{d}_{4,3}\right)$ was calculated. The amount of fat destabilization was calculated by comparing the particle size of ice cream and aged mix using the following equation:

Fat destabilization $(\%)=\frac{\left(\mathrm{d}_{4,3} \text { ice cream }-\mathrm{d}_{4,3} \mathrm{mix}\right)}{\mathrm{d}_{4,3} \text { ice cream }} \times 100$.
Hardness was measured as described previously (Roland et al., 1999a; Karaca et al., 2009). A texture analyzer (TA-XT2 Texture Analyzer; Texture Technologies, Hamilton, MA) equipped with a $25-\mathrm{mm}$ acrylic cylindrical probe was used to compress the ice creams. The measurements were performed using a pre- and post-test speed of $3.00 \mathrm{~mm} / \mathrm{s}$, a test speed of 2.00 $\mathrm{mm} / \mathrm{s}$, a trigger force of $0.1 \mathrm{~N}$, and total distance of 20 $\mathrm{mm}$. Hardness was determined as the peak compression force. After each measurement, the temperature of the sample was assessed with a calibrated thermocouple to ensure that any difference observed in hardness was not due to temperature differences between samples. Melting rate was quantified using the method of Goff and Hartel (2013). The content of a 4-ounce cup of ice cream (approximately $70 \mathrm{~g}$ ) was placed over a metallic mesh inside a funnel and allowed to drain over a beaker at room temperature $\left(20^{\circ} \mathrm{C}\right)$. The amount of melted ice cream inside the beaker was weighed every 10 min for 2 h. The weight of the sample drained over time was plotted, and the melting rate was calculated as the slope of the linear portion of the curve.

\section{Sensory Testing}

Consumer Acceptability. For each batch of ice cream, central location tests were executed with $\sim 100$ people per test. Participants were screened for food allergies and product use (i.e., consumed vanilla ice cream at least once a month). Procedures were exempted from institutional review board review by professional staff in the Penn State Office of Research Protections under the wholesome foods exemption in 45 CFR 46.101(b). Participants provided informed consent via computer and were compensated for their time.

To measure degree of liking, a labeled affective magnitude scale (LAM) was used. The LAM shows similar performance to the widely used 9-point hedonic scale, but it appears to allow better discrimination between highly liked products (Schutz and Cardello, 2001; El Dine and Olabi, 2009), an important consideration for ice cream. Participants were also asked to rate perceived intensity for several attributes of interest, including sweetness, vanilla flavor, creaminess, smoothness, mouth coating, hardness, and melt rate. Although it is not traditional to collect intensity data from untrained panelists (Lawless and Heymann, 2010), gathering this information was desirable because it could help identify the sensory drivers of changes in liking. Recent work suggests that untrained consumers can provide meaningful intensity ratings for complex products $(\mathrm{Li}$ et al., 2014). Ice cream samples were equilibrated in tempering cabinets $\left(-12^{\circ} \mathrm{C}\right)$ until they were served to 
panelists. Samples were presented 1 at a time (monadic sequential presentation) with the 3 -digit blinding codes in counterbalanced order, using a Williams design (Williams, 1949). Each participant received a sample, answering the liking question first and the intensity questions after to avoid biasing the hedonic rating. Data were collected using Compusense Cloud (Compusense Inc., Guelph, ON, Canada).

Discrimination Test. Discrimination tests were used to determine whether consumers could detect differences in fat content in various vanilla ice creams. These tests were performed in 2 sessions: in session 1 , panelists were asked to discriminate between samples that differed in fat content by 2 percentage points; in session 2, panelists were asked to discriminate ice creams samples with a fat difference of 4 percentage points. If a sample was successfully discriminated by the group in session 1, it was not included in session 2 . In each session, panelists were presented with 2 triangle tests and had a 5 min break in between. Each triangle consisted of 2 samples of ice cream with the same fat level and 1 sample with a different fat level; participants had to identify the different sample in a forced-choice task. Approximately 100 participants completed each session. Data were collected using Compusense Cloud (Compusense Inc.).

Storage Stability. After the initial acceptability testing, ice creams were stored in a walk-in freezer $\left(-18^{\circ} \mathrm{C}\right)$ for $19 \mathrm{wk}$. The liking and intensity ratings were then collected a second time, using the methods described above.

\section{Statistical Analysis}

The entire experiment was replicated 3 times. SAS 9.4 (SAS Institute Inc., Cary, NC) was used to perform all statistical analysis, except where otherwise stated. Generally, effects were tested in mixed-model ANOVA via Proc Mixed. Treatments were considered significantly different when $P<0.05$.

Physical Data. One-way ANOVA was used to analyze the physical data. If the overall $\mathrm{F}$ test was significant, differences were determined via Tukey's honest significant difference.

Consumer Acceptability and Storage Stability. Mixed-model ANOVA was used to analyze all sensory data. The model included the effects of treatment, batch, their interaction, panelists nested within batch, and serving position nested within batch. Treatment was the fixed effect, and batch, batch $\times$ treatment, panelist, and position were random effects. If significant differences were found, Tukey's honest significant difference was used to compare the treatments. To assess the effect of fresh vs. stored ice cream, a mixed ANOVA model was used that included the effects of treatment, batch, state (fresh or stored), all 3-way interactions, the date of the sensory test, panelist nested within day of sensory test and serving position nested within day of sensory test. Treatment, state, and their interaction were considered fixed effects, the rest of the terms were random effects. If significant differences were found, Tukey's honest significant difference was applied for the treatment $\times$ state interaction.

Discrimination Test. The number of participants that correctly identified the different sample was computed as the proportion of correct answers and compared against the chance probability $(0.333)$; if the observed proportion deviated significantly from the chance probability, the null hypothesis of no difference was rejected. D-prime values $\left(\mathrm{d}^{\prime}\right)$ were calculated directly in Compusense Cloud (Compusense Inc.).

\section{RESULTS AND DISCUSSION}

\section{Physical Analysis}

The measured total solids, total fat, overrun, and draw temperature of the manufactured ice cream are shown in Table 2. Total solids, overrun, and draw temperature did not significantly differ between samples. The fat contents of all treatments were significantly different from each other, but the values were somewhat higher than expected from the formulation. This may have been due to the sequence in which the treatments were run in the pasteurizer, from high to low fat, which appears to have resulted in a small carryover effect. This order (high to low fat) was intentionally chosen to avoid carryover of maltodextrin from 1 treatment to the other. Regardless of the small carryover effect seen for fat, the different treatment samples still had fat levels that differed systematically, allowing us to compare their properties and address the aims of the study.

The physical parameters measured on the aged mix and ice cream are shown in Table 3. Density and kinematic viscosity decreased with an increase in fat content, a finding that can be explained by the higher maltodextrin content in the reduced-fat ice cream samples. An increase in viscosity with increasing concentrations of polysaccharides was also observed when using inulin and maltodextrin as fat replacement strategies in ice cream formulations (Schmidt et al., 1993; Aykan et al., 2008). In the present study, all mixes were shear thinning with a flow index between 0 and 1 , typical of ice cream mixes (Ohmes et al., 1998; Innocente et al., 2009; Mahdian and Karazhian, 2013).

Mix particle size increased with fat content as expected, because the homogenization pressure was constant for all treatment levels. Innocente et al. (2009) also 
Table 2. Compositional and manufacturing attributes of vanilla ice cream made with decreasing fat content and replacement with maltodextrin $(\mathrm{MD})^{1}$

Treatment

\begin{tabular}{lccrrr}
\cline { 2 - 5 } Attribute & $6 \%$ fat, $8 \% \mathrm{MD}$ & $8 \%$ fat, $6 \% \mathrm{MD}$ & $10 \%$ fat, $4 \% \mathrm{MD}$ & $12 \%$ fat, $2 \% \mathrm{MD}$ & $14 \%$ fat, $0 \% \mathrm{MD}$ \\
\hline Total fat $(\%)$ & $6.58 \pm 0.14^{\mathrm{e}}$ & $8.67 \pm 0.14^{\mathrm{d}}$ & $10.80 \pm 0.14^{\mathrm{c}}$ & $12.91 \pm 0.14^{\mathrm{b}}$ & $14.19 \pm 0.14^{\mathrm{a}}$ \\
Total solids $(\%)$ & $41.46 \pm 0.16^{\mathrm{a}}$ & $41.72 \pm 0.16^{\mathrm{a}}$ & $41.79 \pm 0.16^{\mathrm{a}}$ & $41.81 \pm 0.16^{\mathrm{a}}$ & $41.29 \pm 0.16^{\mathrm{a}}$ \\
Overrun (\%) & $66 \pm 2^{\mathrm{a}}$ & $63 \pm 2^{\mathrm{a}}$ & $63 \pm 2^{\mathrm{a}}$ & $65 \pm 2^{\mathrm{a}}$ & $63 \pm 2^{\mathrm{a}}$ \\
Draw temperature $\left({ }^{\circ} \mathrm{C}\right)$ & $-5.7 \pm 0.2^{\mathrm{a}}$ & $-5.5 \pm 0.2^{\mathrm{a}}$ & $-5.5 \pm 0.2^{\mathrm{a}}$ & $-5.3 \pm 0.2^{\mathrm{a}}$ & $-5.1 \pm 0.2^{\mathrm{a}}$ \\
\hline
\end{tabular}

${ }^{\mathrm{a} e}$ Means with different letters within the same row indicate significant differences $(P<0.05)$.

${ }^{1}$ Results are presented as LSM $\pm \operatorname{SEM}(\mathrm{n}=3)$.

observed this effect when using constant homogenization pressures on ice cream mixes with 5 and $8 \%$ fat content. During dynamic freezing, the milk fat globules partially coalesce, which explains the increase in size measured in the ice cream samples relative to the mix. In a study on the effects of increased protein content on fat destabilization, Daw and Hartel (2015) used particle size analysis to measure the degree of partial coalescence after ice cream freezing. They observed 3 distinct particle size distribution peaks: the first (between 0.3 to $0.4 \mu \mathrm{m})$ corresponded to casein micelles; the second (at approximately $1 \mu \mathrm{m}$ ) corresponded to homogenized fat globules; and a third (above $10 \mu \mathrm{m}$ ) represented destabilized fat clusters. Here, only 1 distribution was observed in the aged mixes and in the ice cream samples; however, the distribution range shifted from 0.1 to $1 \mu \mathrm{m}$ in the aged mixes to 0.1 to $10 \mu \mathrm{m}$ for the ice cream samples, suggesting a degree of partial coalescence (data not shown). The treatments with the highest amount of fat exhibited a larger increase in particle size and a higher degree of fat destabilization. This finding can be explained by the higher probability of droplet collision at higher fat contents. Schmidt et al. (1993) did not observe a change in fat destabilization when replacing approximately $3 \%$ fat with maltodextrin, but Adapa et al. (2000) observed a decrease in fat destabilization when reducing fat content from $12 \%$ to $6 \%$ without replacing the solids, and a further decrease in fat destabilization in an ice cream with $6 \%$ fat when using microcrystalline cellulose and guar gum as fat replacers that was attributed to the increase in mix viscosity.

In the present study, the fat content of the ice creams did not significantly affect instrumental hardness. Roland et al. (1999b) observed a decrease in hardness in fat-free ice creams with added maltodextrin or polydextrose compared with a fat-free ice cream that had a lower solids content. However, the hardness of the ice cream with added maltodextrin was not significantly different from that of a $10 \%$ fat control ice cream. Fat content also did not affect the melting rate of the ice cream treatments under study. This trend was also observed when reducing fat from 4.8 to $2.1 \%$, using maltodextrin or microparticulated whey protein as fat replacers (Schmidt et al., 1993). However, Roland et al. (1999b) observed a faster melting rate in fat-free ice creams when using maltodextrin, polydextrose, or milk protein concentrate, compared with a $10 \%$ fat control

Table 3. Physical characterization of vanilla ice cream with decreasing fat content and replacement with maltodextrin (MD $)^{1}$

\begin{tabular}{|c|c|c|c|c|c|}
\hline \multirow[b]{2}{*}{ Characteristic } & \multicolumn{5}{|c|}{ Treatment } \\
\hline & $6 \%$ fat, $8 \% \mathrm{MD}$ & $8 \%$ fat, $6 \% \mathrm{MD}$ & $10 \%$ fat, $4 \% \mathrm{MD}$ & $12 \%$ fat, $2 \% \mathrm{MD}$ & $14 \%$ fat, $0 \% \mathrm{MD}$ \\
\hline Density $(\mathrm{g} / \mathrm{mL})$ & $1.18 \pm 0.01^{\mathrm{a}}$ & $1.15 \pm 0.01^{\mathrm{ab}}$ & $1.15 \pm 0.01^{\mathrm{ab}}$ & $1.15 \pm 0.01^{\mathrm{ab}}$ & $1.13 \pm 0.01^{\mathrm{b}}$ \\
\hline Kinematic viscosity $\left(\mathrm{mm}^{2} / \mathrm{s}\right)$ & $194 \pm 11^{\mathrm{a}}$ & $188 \pm 11^{\mathrm{a}}$ & $169 \pm 11^{\mathrm{ab}}$ & $134 \pm 11^{\mathrm{b}}$ & $117 \pm 11^{\mathrm{b}}$ \\
\hline Apparent viscosity at $30 \mathrm{~s}^{-1}(\mathrm{~Pa} \cdot \mathrm{s})$ & $0.14 \pm 0.01^{\mathrm{ab}}$ & $0.15 \pm 0.01^{\mathrm{ab}}$ & $0.16 \pm 0.01^{\mathrm{a}}$ & $0.16 \pm 0.01^{\mathrm{ab}}$ & $0.13 \pm 0.01^{\mathrm{b}}$ \\
\hline Flow index & $0.87 \pm 0.03^{\mathrm{a}}$ & $0.83 \pm 0.03^{\mathrm{a}}$ & $0.79 \pm 0.03^{\mathrm{a}}$ & $0.81 \pm 0.03^{\mathrm{a}}$ & $0.83 \pm 0.03^{\mathrm{a}}$ \\
\hline Hardness at $-13.7 \pm 0.7^{\circ} \mathrm{C}(\mathrm{kg})$ & $5.21 \pm 1.17^{\mathrm{a}}$ & $4.84 \pm 1.17^{\mathrm{a}}$ & $4.50 \pm 1.17^{\mathrm{a}}$ & $5.93 \pm 1.17^{\mathrm{a}}$ & $7.45 \pm 1.17^{\mathrm{a}}$ \\
\hline $\begin{array}{l}\text { Melting rate at room temperature }\left(\sim 20^{\circ} \mathrm{C}\right) \\
(\mathrm{g} / \mathrm{min})\end{array}$ & $1.35 \pm 0.10^{\mathrm{a}}$ & $1.32 \pm 0.10^{\mathrm{a}}$ & $1.16 \pm 0.10^{\mathrm{a}}$ & $0.97 \pm 0.10^{\mathrm{a}}$ & $1.09 \pm 0.10^{\mathrm{a}}$ \\
\hline
\end{tabular}

\footnotetext{
${ }^{\mathrm{a}-\mathrm{c}}$ Means with different letters within the same row indicate significant differences $(P<0.05)$.

${ }^{1}$ Results are presented as LSM $\pm \operatorname{SEM}(\mathrm{n}=3)$.

${ }^{2} \mathrm{~d}_{4,3}=$ volume-weighted mean.
} 
ice cream. Moreover, the use of increasing concentrations of inulin as a fat replacer increased the melting rate of ice cream (Tiwari et al., 2015).

Consumer Acceptability. A total of 292 participants evaluated the fresh ice creams. Of these, $32 \%$ were men and $55 \%$ were in their 20 s and 30 s. Via self-report, $81 \%$ of the participants reported consuming vanilla ice cream at least 2 to 3 times per month, suggesting most were regular users of the product category.

Strikingly, at baseline, overall liking did not significantly change with the reduction in fat content from 14 to $6 \%$ when total solids were held constant (Figure 1). Previously, Li et al. (1997) observed that when reducing the fat content from 10 to $0 \%$ in vanilla ice creams and replacing the solids with polydextrose, a fat reduction of 2 percentage points resulted in a decrease of 0.5 to 0.6 units in consumer liking scores on a 9-point hedonic scale. Guinard et al. (1996) also observed a decrease in overall liking when reducing fat content from 18 to $8 \%$; however, they also observed that sugar content was a stronger determinant of liking than fat level. Conversely, Prindiville et al. (1999) reported no significant difference in consumer acceptability of chocolate ice creams with fat content between 0.5 and $9 \%$; they speculated that the lack of difference was due to the use of polydextrose and microparticulated whey proteins as fat replacers in their formulations. However, in that study, use of a 9-point hedonic scale may have obscured differences in liking, because ice cream is a highly liked product (Schutz and Cardello, 2001; El Dine and Olabi, 2009). Although others have also studied the acceptability of reduced-fat ice creams (Aykan et al., 2008;

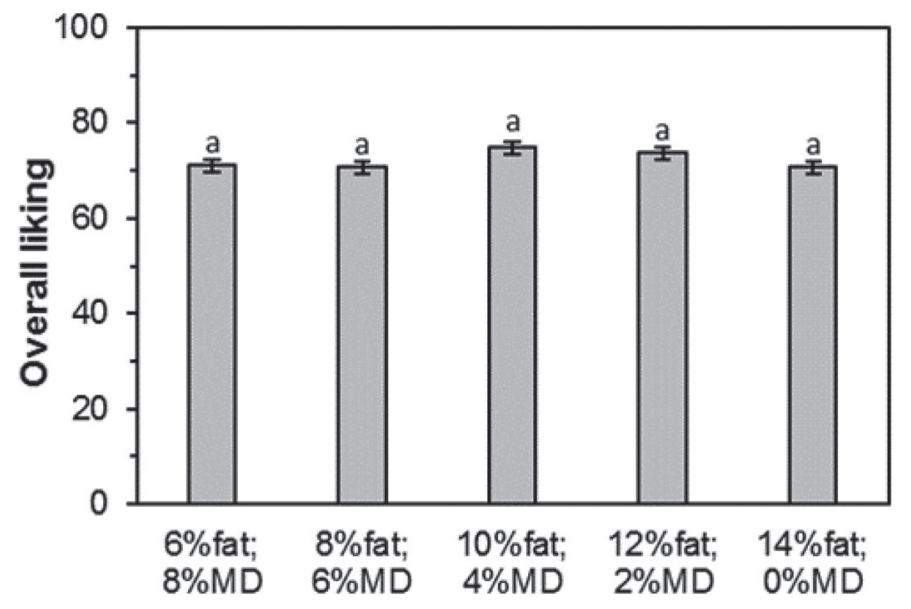

Fat content; Maltodextrin content

Figure 1. Overall liking of fresh vanilla ice cream with decreasing fat content and replacement with maltodextrin (MD). Results are presented as LSM \pm SEM $(\mathrm{n}=292)$. Different letters indicate significant differences between treatments $(P<0.05)$.
Tiwari et al., 2015), the interpretability of these reports is limited by the small number of participants.

At baseline, sweetness did not differ significantly across treatment levels (not shown; means from 60.5 to 62.2 ), congruent with the pattern observed for overall liking. Previously, descriptive analysis with trained panelists has suggested that sweetness may increase when maltodextrin, polydextrose, or milk protein concentrate (Roland et al., 1999b) or polydextrose or microparticulated whey proteins (Prindiville et al., 1999) are used to replace fat in ice creams. We did not observe such a difference with consumers.

Ratings of vanilla flavor did not differ significantly across treatment levels (not shown; means from 59.3 to 61.6). Previously, high fat content was shown to delay the perception of vanilla flavor when no bulking agents or fat replacers were added to the mix (Li et al., 1997; Frøst et al., 2005).

The hardness of the ice creams as perceived by consumers did not differ significantly across the fat levels studied (not shown; means from 45.2 to 66.9). Sensory ratings of hardness have been found to be higher in ice creams with $10 \%$ fat compared with a product containing $4 \%$ fat and no fat replacers (Stampanoni Koeferli et al., 1996; Liou and Grün, 2007). This discrepancy was probably due to our use of maltodextrin as a bulking agent.

Melting rate differed across treatments (not shown; means from 40.3 to 50.4). Others have reported that the use of fat replacers often produced slow-melting fat-reduced ice creams when using maltodextrin, polydextrose, or milk protein concentrate (Roland et al., 1999b), or inulin (Tiwari et al., 2015).

In the present study, ratings of creaminess and smoothness were significantly different across fat levels when maltodextrin was used as a fat replacer (Figure 2 ). Ice cream with $14 \%$ fat and no maltodextrin was significantly less smooth than the other treatments, and significantly less creamy than the ice cream with $10 \%$ fat, $4 \%$ maltodextrin. Creaminess is a multimodal sensation: for a food product to be perceived as creamy, multiple sensory inputs are involved, including taste, texture, and smell (Kilcast and Clegg, 2002; Jervis et al., 2014). Liou and Grün (2007) showed a higher rating in creaminess and smoothness (by descriptive panel) for ice creams with $10 \%$ fat than for ice creams with $4 \%$ fat and without fat replacement. Moreover, Roland et al. (1999a) observed an increase in creamy flavor with an increase in fat content and no fat replacement.

Our consumer testers were given no definitions when asked to rate these attributes in the ice creams. It is likely that each participant used a personal definition or interpretation when rating the intensity they perceived. This may have affected our results and increased the 
Table 4. Compositional and manufacturing characteristics of vanilla ice cream made with decreasing fat content and replacement with maltodextrin (MD) for the discrimination tests ${ }^{1}$

Treatment

\begin{tabular}{lccccc}
\cline { 2 - 6 } Attribute & $6 \%$ fat, $8 \% \mathrm{MD}$ & $8 \%$ fat, $6 \% \mathrm{MD}$ & $10 \%$ fat, $4 \% \mathrm{MD}$ & $12 \%$ fat, $2 \% \mathrm{MD}$ & $14 \%$ fat, $0 \% \mathrm{MD}$ \\
\hline Total fat $(\%)$ & $6.33 \pm 0.01^{\mathrm{e}}$ & $8.41 \pm 0.01^{\mathrm{d}}$ & $10.41 \pm 0.00^{\mathrm{c}}$ & $12.43 \pm 0.01^{\mathrm{b}}$ & $14.21 \pm 0.04^{\mathrm{a}}$ \\
Total solids $(\%)$ & $41.48 \pm 0.05^{\mathrm{a}}$ & $41.76 \pm 0.04^{\mathrm{a}}$ & $41.47 \pm 0.08^{\mathrm{a}}$ & $41.46 \pm 0.24^{\mathrm{a}}$ & $41.27 \pm 0.09^{\mathrm{a}}$ \\
Overrun (\%) & $69.0 \pm 0.4^{\mathrm{a}}$ & $68.2 \pm 0.2^{\mathrm{ab}}$ & $63.8 \pm 0.7^{\mathrm{c}}$ & $64.4 \pm 0.6^{\mathrm{c}}$ & $65.4 \pm 1.1^{\mathrm{bc}}$ \\
Draw temperature $\left({ }^{\circ} \mathrm{C}\right)$ & $-6.0 \pm 0.0^{\mathrm{a}}$ & $-5.9 \pm 0.1^{\mathrm{a}}$ & $-5.9 \pm 0.1^{\mathrm{a}}$ & $-5.9 \pm 0.1^{\mathrm{a}}$ & $-5.8 \pm 0.2^{\mathrm{a}}$ \\
\hline
\end{tabular}

${ }^{a}$ Means with different letters within the same row indicate significant differences $(P<0.05)$.

${ }^{1}$ Results are presented as LSM $\pm \operatorname{SEM}(\mathrm{n}=3)$.

variability in the measurement. Furthermore, due to the phase transition from solid to liquid during consumption, many attributes (e.g., flavor release, melting rate, and hardness) change over time. Nonetheless, our
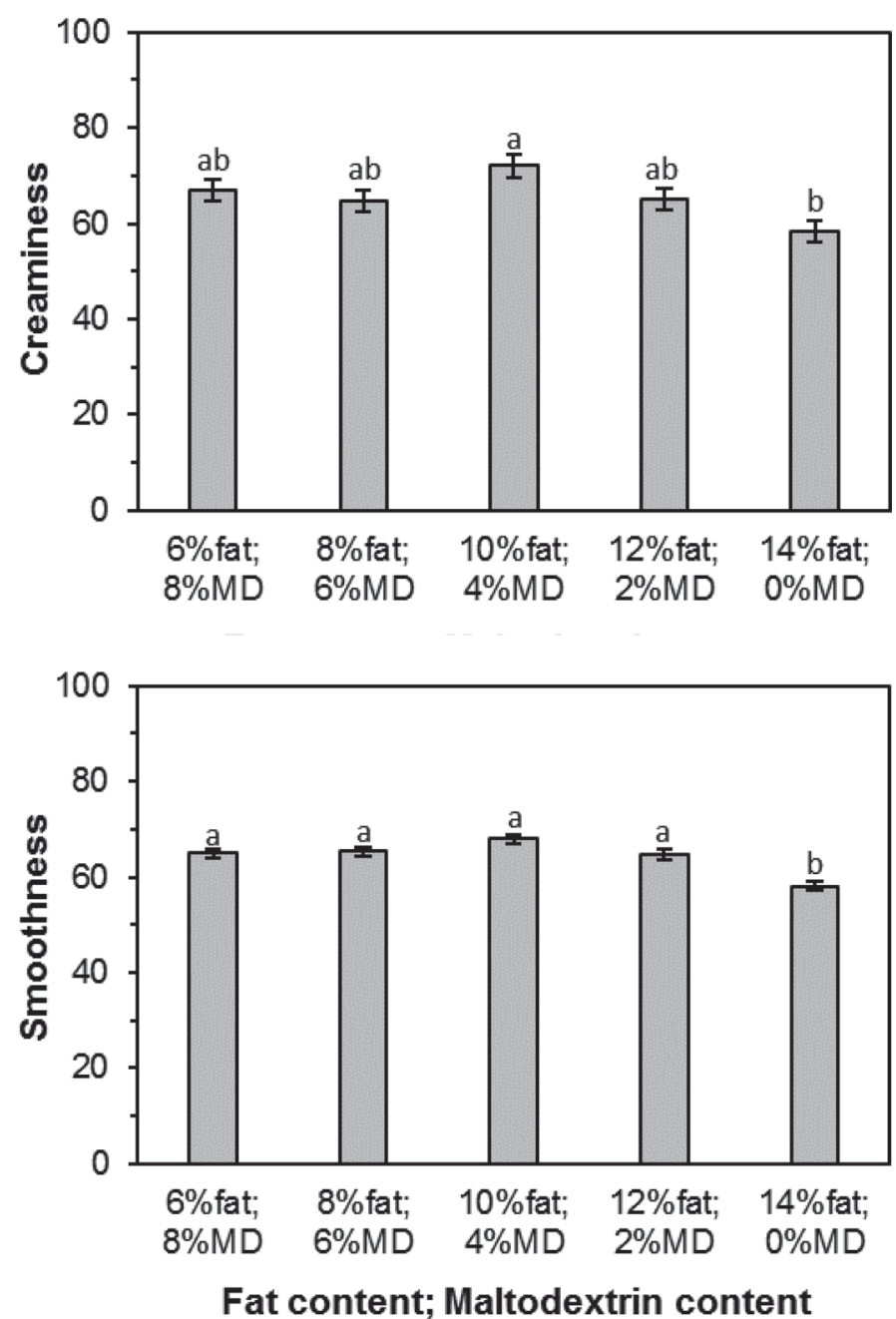

Figure 2. Creaminess and smoothness of fresh vanilla ice cream with decreasing fat content and replacement with maltodextrin (MD), as perceived by consumers. Results are presented as LSM \pm SEM ( $\mathrm{n}=$ 292). Different letters within the same descriptor indicate significant differences between treatments $(P<0.05)$. focus was primarily on consumers. Future work with temporal methods using trained panelists is warranted to understand the time-dependent changes caused by the reduction of fat for these particular attributes.

Discrimination Testing. Because we observed no significant differences in overall liking, we conducted a series of discrimination tests to determine if our consumers could differentiate between ice creams with small reductions in fat when solids were held constant. We prepared a new set of ice cream samples for this test, using the same formulations given in Table 1. Total solids, fat content, overrun, and draw temperature were measured to verify formulation and manufacturing conditions; these results are summarized in Table 4. Total solids and draw temperature were not significantly different across treatment levels. As designed, total fat was significantly different across treatment levels. Also, overrun decreased significantly with fat content; this was not anticipated during the manufacturing process and may affect interpretation of the results, although the overall effect size was very small.

Results for both series of discrimination testing are summarized in Table 5 . The first series systematically compared all ice creams with a fat difference of 2 percentage points (e.g., 6 vs. $8 \%, 8$ vs. 10\%). Collectively, participants were unable to differentiate between ice creams with fat levels that differed by 2 percentage points when total solids were held constant with maltodextrin. In contrast, participants discriminated between the nominally 12 and $14 \%$ fat samples (with an actual difference in fat of $1.78 \%$; see Table 4 ). This effect was likely due to the complete absence of maltodextrin in the $14 \%$ fat samples, because it may contribute some distinct character to the ice cream with $12 \%$ fat.

In a second series of tests, all samples that had a fat difference of 4 percentage points and contained maltodextrin were compared. The sample with $14 \%$ fat was excluded from this series because it had been effectively discriminated in the previous series (when the fat difference was less than 2 percentage points). Participants were not able to discriminate between the samples with 8 and $12 \%$ fat. However, they could discriminate 
Table 5. Results for the discrimination of ice creams with fat difference of 2 and 4 percentage points

\begin{tabular}{|c|c|c|c|c|c|c|}
\hline \multirow[b]{2}{*}{ Attribute } & \multicolumn{4}{|c|}{ Fat comparisons, 2 percentage points ${ }^{2}$} & \multicolumn{2}{|c|}{$\begin{array}{c}\text { Fat comparisons, } 4 \text { percentage } \\
\text { points }^{2}\end{array}$} \\
\hline & $6 \%$ vs. $8 \%$ & $8 \%$ vs. $10 \%$ & $10 \%$ vs. $12 \%$ & $12 \%$ vs. $14 \%$ & $6 \%$ vs. $10 \%$ & $8 \%$ vs. $12 \%$ \\
\hline Panelists (no.) & 99 & 102 & 99 & 101 & 93 & 93 \\
\hline Proportion of correct answers & 0.36 & 0.27 & 0.32 & 0.43 & 0.42 & 0.23 \\
\hline $\mathrm{d}^{\prime 1}$ & 0.58 & 0.00 & 0.00 & 1.05 & 1.01 & 0.00 \\
\hline
\end{tabular}

${ }^{1} \mathrm{~d}^{\prime}$ is the sensory difference, calculated from the proportion of correct answers using Thurstonian modeling.

${ }^{2}$ Treatments: $6 \%=6 \%$ fat $+8 \%$ maltodextrin; $8 \%=8 \%$ fat $+6 \%$ maltodextrin; $10 \%=10 \%$ fat $+4 \%$ maltodextrin; $12 \%=12 \%$ fat $+2 \%$ maltodextrin; $14 \%=14 \%$ fat $+0 \%$ maltodextrin.

between the samples with 6 and $10 \%$ fat content. It seems likely that this was due to a change in the flavor profile of the samples because of a substantial increase in maltodextrin content, although we could not rule out the small difference in overrun. These data suggest that quantitation is needed of the underlying differences in the sensory profiles of ice creams with different fat and maltodextrin content via descriptive analysis. Nonetheless, the inability of consumers to distinguish between samples that differed in fat by 2 percentage points was striking.

Storage Stability. The quality of ice cream typically decreases over storage because of an increase in size of ice crystals (Goff and Hartel, 2013), among other factors. A substantial amount of work has focused on the effects of storage temperature and temperature fluctuations on ice-crystal growth (Donhowe and Hartel, 1996a,b; Park et al., 2015), viscoelastic behavior (Tsevdou et al., 2015), and sensory quality, using descriptive panels (Conforti, 1994; Buyck et al., 2011). However, few studies (Tsevdou et al., 2015) have investigated changes in consumer acceptability of ice cream after storage.

In the present study, our ice cream samples were re-evaluated for consumer acceptability after $19 \mathrm{wk}$ of storage at approximately $-18^{\circ} \mathrm{C}$. A total of 282 consumers tested the samples. Of this total, $\sim 40 \%$ were men and $\sim 54 \%$ were in their 20 s and 30 s; $\sim 79 \%$ reported consuming vanilla ice cream at least 2 to 3 times per month. Figure 3 shows the sensory results for the fresh and stored ice creams for selected descriptors. We observed no significant difference in liking after storage across treatment levels, and all liking ratings after storage were lower than those obtained when the ice creams were tested fresh. However, only the aged samples with 8 and $10 \%$ fat were statistically lower in overall liking than the fresh samples. The stabilizer system used in the present study contained propylene glycol monostearate, which is known to enhance shelf life and may have influenced the results (Aleong et al., 2008). In a study of the sensory quality of frozen desserts with different sources of milk fat, Abd El-Rahman et al. (1997) reported a decrease in overall liking following storage. Likewise, Tsevdou et al. (2015), using a trained panel $(\mathrm{n}=10)$, observed a decrease in acceptability of ice cream over time as well as a storage-temperature dependence, although obtaining affective ratings from trained panelists is generally not advised.

As in the baseline sensory testing, participants were also asked to rate the perceived intensity of various attributes (see above). Sweetness, vanilla flavor, creaminess, smoothness, and mouth coating were not significantly different across treatment levels in the aged ice cream (not shown). However, for perceived hardness, the aged ice cream with $12 \%$ fat had the lowest intensity score and was significantly different from the aged ice creams with 8,10 , and $14 \%$ fat. As for melting rate, the aged ice cream with $8 \%$ fat had the lowest score and was significantly different from the aged ice cream with $12 \%$ fat. Previously, using a trained sensory panel, Buyck et al. (2011) observed that when solids were not replaced, reduced-fat ice cream (5.2\% fat) was perceived as less creamy, icier, and colder than a full-fat product $(10.3 \%$ fat) at storage temperatures ranging from -23.3 to $-45.6^{\circ} \mathrm{C}$. Moreover, Conforti (1994) observed a reduction in sweetness and vanilla intensity ratings from a trained descriptive panel in ice creams with fat content ranging from 10 to $16 \%$ after a heat shock treatment. In the present study, although sweetness, vanilla flavor, and mouth coating ratings appeared to be lower after storage than with the fresh samples, the difference was not statistically significant (data not shown). Furthermore, the aged ice cream with $10 \%$ fat was significantly less creamy and smooth, was significantly harder, and had a slower melting rate than the fresh ice cream. The ice cream with $12 \%$ fat was significantly less hard and had a faster melting rate after storage than the fresh ice cream. In future work, a trained panel is needed to confirm the differences perceived by consumers in this study. 

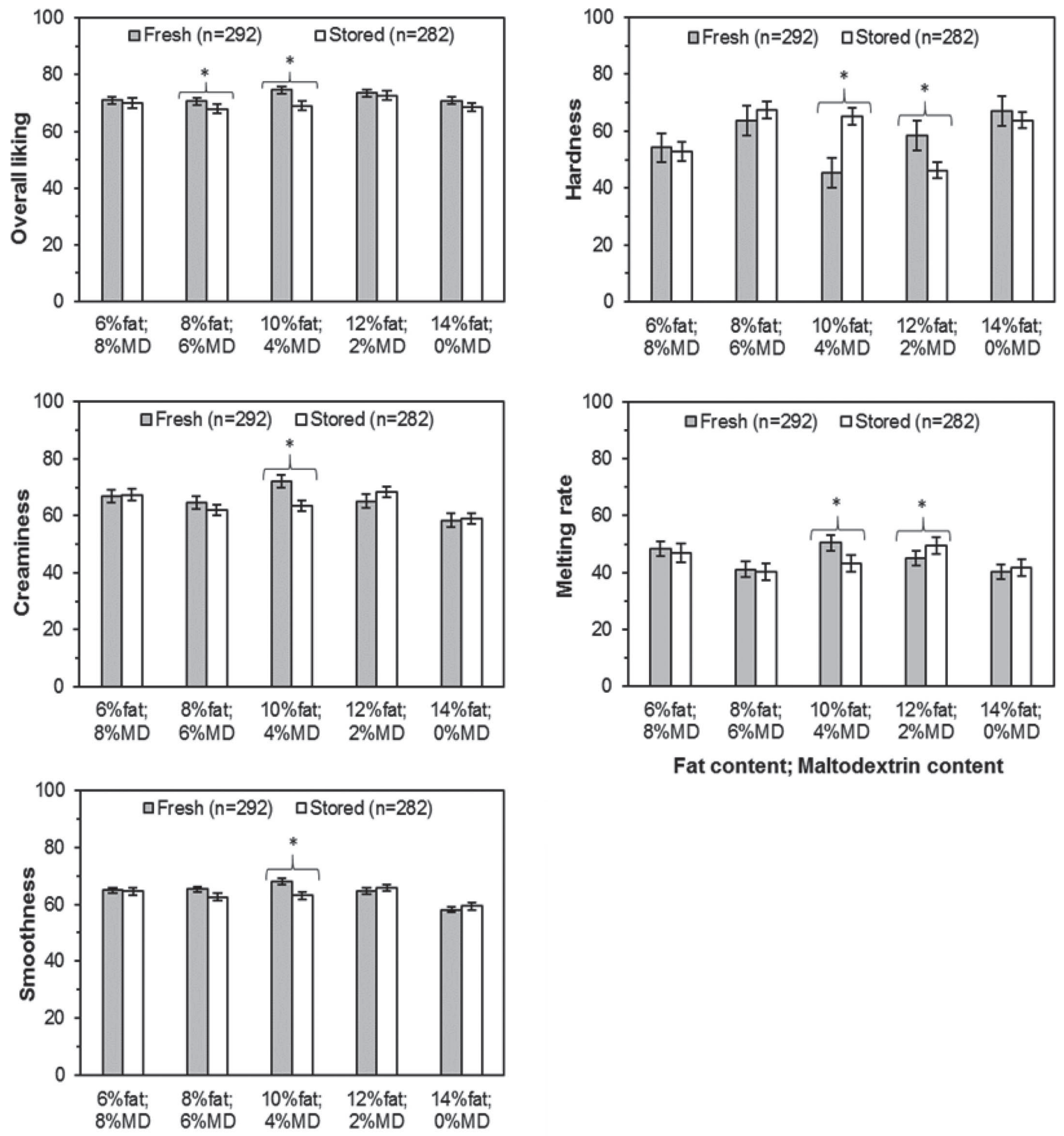

Fat content; Maltodextrin content

Fat content; Maltodextrin content

Figure 3. Overall liking and sensory descriptors of fresh and stored ice creams with decreasing fat content and replacement with maltodextrin $(\mathrm{MD})$. Results are presented as LSM \pm SEM $(\mathrm{n}=292)$. Asterisks within the same treatment level indicate significant differences in the state (fresh or stored) $\times$ treatment effect $(P<0.05)$. 


\section{CONCLUSIONS}

When the fat content of ice cream was reduced from 14 to $6 \%$ with solids held constant by adding maltodextrin, the physical properties of the products were altered. Critically, however, these changes were not sufficient to produce a difference in overall liking, when tasted fresh or after storage. Moreover, regular consumers of vanilla ice cream were unable to distinguish a fat difference of 2 percentage points in samples that contained maltodextrin, or a difference of 4 percentage points between ice creams with 8 and $12 \%$ fat and containing maltodextrin. The use of maltodextrin as a bulking agent may be a feasible for reducing the energy density of vanilla ice cream, as well as a way to reduce production costs. Nonetheless, manufacturers should evaluate this alternative in the context of their own formulations, manufacturing processes, and brand identity.

\section{ACKNOWLEDGMENTS}

This manuscript is based in part on support by the National Institute of Food and Agriculture, USDA, Hatch project 4565 . We thank Terry Grove and the Berkey Creamery at Penn State for assistance with ice cream freezing and the Penn State Sensory Evaluation Center for assistance in performing consumer testing, and Tate and Lyle for providing maltodextrin for the study.

\section{REFERENCES}

Abd El-Rahman, A. M., S. I. Shalabi, R. Hollender, and A. Kilara. 1997. Effect of milk fat fractions on the sensory evaluation of frozen desserts. J. Dairy Sci. 80:1936-1940. https://doi.org/10.3168/ jds.S0022-0302(97)76133-2.

Adapa, S., H. Dingeldein, K. A. Schmidt, and T. J. Herald. 2000. Rheological properties of ice cream mixes and frozen ice creams containing fat and fat replacers. J. Dairy Sci. 83:2224-2229. https:// doi.org/10.3168/jds.S0022-0302(00)75106-X.

Akoh, C. C. 1998. Fat replacers. Food Technol. 52:47-53. https://doi. org/10.1016/0924-2244(94)90043-4.

Aleong, J. M., S. Frochot, and H. D. Goff. 2008. Ice recrystallization inhibition in ice cream by propylene glycol monostearate. J. Food Sci. 73:E463-468. https://doi.org/10.1111/j.1750-3841.2008.00954.x.

ASTM International. 2005. Standard Test Method for Viscosity by Dip-Type Viscosity Cups. ASTM International, West Conshohocken, PA. https://doi.org/10.1520/D4212-99.

Aykan, V., E. Sezgin, and Z. B. Guzel-Seydim. 2008. Use of fat replacers in the production of reduced-calorie vanilla ice cream. Eur. J. Lipid Sci. Technol. 110:516-520. https://doi.org/10.1002/ ejlt. 200700277.

Buyck, J. R., R. J. Baer, and J. Choi. 2011. Effect of storage temperature on quality of light and full-fat ice cream. J. Dairy Sci. 94:2213-2219. https://doi.org/10.3168/jds.2010-3897.

Conforti, F. D. 1994. Effect of fat content and corn sweeteners on selected sensory attributes and shelf stability of vanilla ice cream. Int. J. Dairy Technol. 47:69-75. https://doi. org/10.1111/j.1471-0307.1994.tb01275.x.
Da Silva, V.M., V.P.R. Minim, M.A.M. Ferreira, P.H. de Paula Souza, L.E. da Silva Moraes, and L.A. Minim. 2014. Study of the perception of consumers in relation to different ice cream concepts. Food Qual. Prefer. 36:161-168. https://doi.org/10.1016/j. foodqua1.2014.04.008.

Daw, E., and R. W. Hartel. 2015. Fat destabilization and melt-down of ice creams with increased protein content. Int. Dairy J. 43:33-41. https://doi.org/10.1016/j.idairyj.2014.12.001.

Donhowe, D. P., and R. W. Hartel. 1996a. Recrystallization of ice during bulk storage of ice cream. Int. Dairy J. 6:1209-1221. https:// doi.org/10.1016/S0958-6946(96)00030-1.

Donhowe, D. P., and R. W. Hartel. 1996b. Recrystallization of ice in ice cream during controlled accelerated storage. Int. Dairy J. 6:1191-1208. https://doi.org/10.1016/S0958-6946(96)00029-5.

El Dine, A. N., and A. Olabi. 2009. Effect of reference foods in repeated acceptability tests: Testing familiar and novel foods using 2 acceptability scales. J. Food Sci. 74:S97-S106. https://doi. org/10.1111/j.1750-3841.2008.01034.x.

FDA. Code of federal regulations. Accessed Feb. 16, 2016. http:// www.ecfr.gov

Frøst, M. B., H. Heymann, W. L. P. Bredie, G. B. Dijksterhuis, and M. Martens. 2005. Sensory measurement of dynamic flavour intensity in ice cream with different fat levels and flavourings. Food Qual. Prefer. 16:305-314. https://doi.org/10.1016/j. foodqua1.2004.05.009.

Goff, H. D., and R. W. Hartel. 2013. Ice Cream. 7th ed. Springer, New York.

Goff, H. D., E. Verespej, and A. K. Smith. 1999. A study of fat and air structures in ice cream. Int. Dairy J. 9:817-829. https://doi. org/10.1016/S0958-6946(99)00149-1.

Guinard, J., L. Mori, B. Uatoni, D. Panyam, and A. Kilara. 1997. Sugar and fat effects on sensory properties of ice cream. J. Food Sci. 62:1087-1094.

Guinard, J. X., C. Zoumas-Morse, L. Mori, D. Panyam, and A. Kilara. 1996. Effect of sugar and fat on the acceptability of vanilla ice cream. J. Dairy Sci. 79:1922-1927. https://doi.org/10.3168/jds. S0022-0302(96)76561-X.

Innocente, N., M. Biasutti, E. Venir, M. Spaziani, and G. Marchesini. 2009. Effect of high-pressure homogenization on droplet size distribution and rheological properties of ice cream mixes. J. Dairy Sci 92:1864-1875. https://doi.org/10.3168/jds.2008-1797.

Jervis, S. M., P. Gerard, S. Drake, K. Lopetcharat, and M. A. Drake. 2014. The perception of creaminess in sour cream. J. Sens. Stud. 29:248-257. https://doi.org/10.1111/joss.12098.

Karaca, O. B., M. Güven, K. Yasar, S. Kaya, and T. Kahyaoglu. 2009. The functional, rheological and sensory characteristics of ice creams with various fat replacers. Int. J. Dairy Technol. 62:93-99. https://doi.org/10.1111/j.1471-0307.2008.00456.x.

Kilcast, D., and S. Clegg. 2002. Sensory perception of creaminess and its relationship with food structure. Food Qual. Prefer. 13:609623. https://doi.org/10.1016/S0950-3293(02)00074-5.

Lawless, H. T., and H. Heymann. 2010. Sensory Evaluation of Food. Principles and Practice. 2nd ed. Springer, New York, NY.

Li, B., J. E. Hayes, and G. R. Ziegler. 2014. Interpreting consumer preferences: Physicohedonic and psychohedonic models yield different information in a coffee-flavored dairy beverage. Food Qual. Prefer. 36:27-32. https://doi.org/10.1016/j.foodqua1.2014.03.001.

Li, Z., R. Marshall, H. Heymann, and F. Lakdas. 1997. Effect of milk fat content on flavor perception of vanilla ice cream. J. Dairy Sci. 80:3133-3141.

Liou, B. K., and I. U. Grün. 2007. Effect of fat level on the perception of five flavor chemicals in ice cream with or without fat mimetics by using a descriptive test. J. Food Sci. 72: https://doi. org $/ 10.1111 /$ j.1750-3841.2007.00494.x.

Mahdian, E., and R. Karazhian. 2013. Effect of fat replacers and stabilizers on rheological, physicochemical and sensory properties of reduced-fat ice cream. J. Agric. Sci. Technol.; JAST 15:1163-1174.

McClements, D. J. 2015. Reduced-fat foods: The complex science of developing diet-based strategies for tackling overweight and obesity. Adv. Nutr. 6:338S-352S. https://doi.org/10.3945/an.114.006999. 
Méndez-Velasco, C., and H. D. Goff. 2012. Fat structure in ice cream: A study on the types of fat interactions. Food Hydrocoll. 29:152159. https://doi.org/10.1016/j.foodhyd.2012.02.002.

Ohmes, R. L., R. T. Marshall, and H. Heymann. 1998. Sensory and physical properties of ice creams containing milk fat or fat replacers. J. Dairy Sci. 81:1222-1228. https://doi.org/10.3168/jds. S0022-0302(98)75682-6.

Park, S. H., Y. Jo, J. Chun, G. Hong, M. Davaatseren, and M. Choi. 2015. Effect of frozen storage temperature on the quality of premium ice cream. Korean J. Food Sci. Anim. Resour. 35:793-799. https://doi.org/10.5851/kosfa.2015.35.6.793.

Prindiville, E. A., R. T. Marshall, and H. Heymann. 1999. Effect of milk fat on the sensory properties of chocolate ice cream. J. Dairy Sci. 83:1425-1432. https://doi.org/10.3168/jds.S00220302(99)75369-5.

Roland, A. M., L. G. Phillips, and K. J. Boor. 1999a. Effects of fat content on the sensory properties, melting, color, and hardness of ice cream. J. Dairy Sci. 82:32-38.

Roland, A. M., L. G. Phillips, and K. J. Boor. 1999b. Effects of fat replacers on the sensory properties, color, melting, and hardness of ice cream. J. Dairy Sci. 82:2094-2100. https://doi.org/10.3168/ jds.S0022-0302(99)75451-2.

Schmidt, K., A. Lundy, J. Reynolds, and L.N. Yee. 1993. Carbohydrate or protein based fat mimicker effects on ice milk properties. J. Food Sci. 58:761-763. https://doi.org/10.1111/j.1365-2621.1993. tb09353.x.
Schutz, H. G., and A. V. Cardello. 2001. A labeled affective magnitude (LAM) scale for assessing food liking/disliking. J. Sens. Stud. 16:117-159. https://doi.org/10.1111/j.1745-459X.2001.tb00293.x.

Sonwane, R. S., and A. S. Hembade. 2014. Sensorial quality of dietetic soft serve ice cream prepared by using different proportions of maltodextrin. Int. J. Curr. Res. Acad. Rev. 2:51-55.

Specter, S. E., and C. S. Setser. 1994. Sensory and physical-properties of a reduced-calorie frozen dessert system made with milkfat and sucrose substitutes. J. Dairy Sci. 77:708-717. https://doi. org/10.3168/jds.S0022-0302(94)77004-1.

Stampanoni Koeferli, C. R., P. Piccinali, and S. Sigrist. 1996. The influence of fat, sugar and non-fat milk solids on selected taste, flavor and texture parameters of a vanilla ice cream. Food Qual. Prefer. 7:69-79

Tiwari, A., H. K. Sharma, N. Kumar, and M. Kaur. 2015. The effect of inulin as a fat replacer on the quality of low-fat ice cream. Int. J. Dairy Technol. 68:374-380. https://doi.org/10.1111/14710307.12176 .

Tsevdou, M., E. Gogou, E. Dermesonluoglu, and P. Taoukis. 2015. Modelling the effect of storage temperature on the viscoelastic properties and quality of ice cream. J. Food Eng. 148:35-42. https://doi.org/10.1016/j.jfoodeng.2014.07.002.

Williams, E. J. 1949. Experimental designs balanced for the estimation of residual effects of treatments. Aust. J. Sci. Res. Ser. A $2: 149-168$. 